\title{
Measuring the QT interval on the go
}

\author{
William F. McIntyre ${ }^{1}$, Carlos A. Morillo² \\ ${ }^{1}$ Cardiac Electrophysiology and Peri-Operative Medicine Division of Cardiology PhD Candidate, \\ Health Research Methods, McMaster University, Hamilton, Ontario, Canada \\ ${ }^{2}$ Division of Cardiology, Department of Cardiac Sciences, Libin Cardiovascular Institute of Alberta, \\ University of Calgary, Foothills Medical Center, Calgary, Alberta, Canada
}

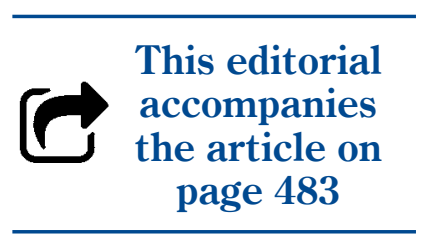

Since March 2019, the coronavirus disease 2019 (COVID-19) pandemic has dominated news cycles, challenged politics and inspired scientists. Many of

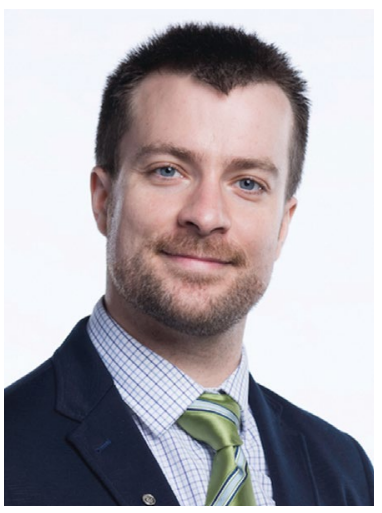
the early candidate drugs to help fight this deadly virus were existing anti-infective agents. Among them were azithromycin, hydroxychloroquine, lopinavir and ritonavir - drugs that are known to prolong the QT interval, and as a consequence, increase an individual's risk of sudden cardiac death. Widespread use and research with these drugs led to a larger need to monitor electrocardiograms (ECG) in these patients, ideally without bringing COVID-19 infected patients in contact with healthcare personnel and other patients [1].

In the current issue of the journal, Abellas-Sequeiros et al. [2] report an experience using a hand-held ECG-recording device to measure the QTc interval in patients with COVID-19. The authors used the KardiaMobile6L ${ }^{\circledR}$ 6-lead ECG to make recordings at varying frequencies in patients who were taking azithromycin, hydroxychloroquine, lopinavir/ritonavir, or combinations of these drugs. Over a mean follow-up of $6.2 \pm 8.4$ days,

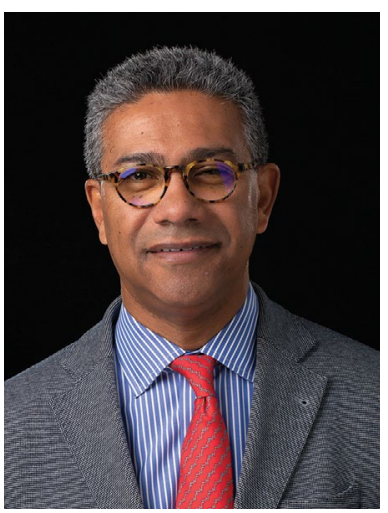

they observed mean QTc interval prolongations of $28 \mathrm{~ms}$ in patients taking two drugs and mean QTc interval prolongations of $41 \mathrm{~ms}$ in patients taking 3 drugs. A total of 12 of the 70 patients in their study had their therapies changed because of increases in their QTc. The authors concluded that portable ECG-recorders are a useful and reliable tool for QT interval monitoring in COVID-19 patients.

Myriad studies have now refuted the efficacy of azithromycin, hydroxychloroquine, and lopinavir/ritonavir across the spectrum of patients who have or are at risk for COVID-19 [3-6]. However, the need for convenient and reliable ways to measure the QT interval persists. Several common classes of drugs are known to prolong the QT and are frequently administered in outpatient settings (Table 1) [7]. The authors have clearly demonstrated the feasibility of using hand-held ECG technology to monitor the QT interval in ambulatory patients who have started a new drug therapy. Clinicians should consider this approach in select patients to minimize hospitalizations and to maximize convenience and compliance.

Conflict of interest: None declared 
Table 1. QT-prolonging drugs that could be monitored using ambulatory hand-held electrocardiogram.

\begin{tabular}{ll}
\hline Anti-arrhythmics & Anti-migraine \\
Anti-biotics & Anti-malarials \\
Anti-depressants & Anti-protozoals \\
Anti-emetics & Anti-psychotic \\
Anti-histamines & Anti-rheumatics \\
Anti-fungals & Methadone \\
\hline
\end{tabular}

\section{References}

1. Li G, Saguner AM, An J, et al. Cardiovascular disease during the COVID-19 pandemic: Think ahead, protect hearts, reduce mortality. Cardiol J. 2020; 27(5): 616-624, doi: 10.5603/ CJ.a2020.0101, indexed in Pubmed: 32789839.

2. Abellas-Sequeiros M, Lozano-Granero C, Garcia-Sebastian C, et al. Monitoring of QTc interval in patients with COVID-19. First experience with a portable ECG-recording device. Cardiol J.
2021; 28(3): 483-485, doi: 10.5603/CJ.a2021.0033, indexed in Pubmed: 33843037.

3. Horby P, Mafham M, Linsell L, et al. RECOVERY Collaborative Group. Effect of hydroxychloroquine in hospitalized patients with COVID-19. N Engl J Med. 2020; 383(21): 2030-2040, doi: 10.1056/NEJMoa2022926, indexed in Pubmed: 33031652.

4. Cavalcanti AB, Zampieri FG, Rosa RG, et al. Hydroxychloroquine with or without azithromycin in mild-to-moderate COVID-19. N Engl J Med. 2020; 383(21): 2041-2052, doi: 10.1056/NEJMoa2019014, indexed in Pubmed: 32706953.

5. Mitjà O, Corbacho-Monné M, Ubals $\mathrm{M}$, et al. A Cluster-Randomized Trial of Hydroxychloroquine for Prevention of COVID-19. N Engl J Med. 2021; 384(5): 417-427, doi: 10.1056/ NEJMoa2021801, indexed in Pubmed: 33289973.

6. Cao B, Wang $\mathrm{Y}$, Wen D, et al. A trial of lopinavir-ritonavir in adults hospitalized with severe COVID-19. N Engl J Med. 2020; 382(19): 1787-1799, doi: 10.1056/NEJMoa2001282, indexed in Pubmed: 32187464.

7. Nachimuthu S, Assar MD, Schussler JM. Drug-induced QT interval prolongation: mechanisms and clinical management. Ther Adv Drug Saf. 2012; 3(5): 241-253, doi: 10.1177/2042098612454283, indexed in Pubmed: 25083239. 